\title{
Health, healing and shalom: Frontiers and challenges for Christian health missions, by Bryant L. Myers, Erin Dufault-Hunter, Isaac B. Voss, Eds. Wm Carey Library
}

\section{Press. 2015}

\author{
Cynthia B. Hale
}

\begin{abstract}
${ }^{a}$ MD, MPH, FAAP, former medical missionary, United Mission to Nepal, Interserve USA; former associate professor, Department of Community Medicine, Tribhuvan University Institute of Medicine, Kathmandu, Nepal.
\end{abstract}

Technological advances in medical care have led healthcare practitioners in so-called developing countries to copy the biomedical model currently in use in the USA and other Western countries. When my husband, Dr. Thomas Hale, Jr, and I first went to Nepal as medical missionaries, we went thoroughly prepared according to the biomedical model of disease, and we were also prepared to share our faith in Christ, disciple believers, and contribute to the growth of the Church in Nepal. It was in Nepal that we learned not to separate our ministry into secular and sacred compartments. We also observed that the strictly biomedical model of medical care was inadequate for helping people who have a much more holistic understanding of health and disease, people who live in traditional societies and societies in transition. We came to realize that a strictly biomedical model for treating the ill does not correlate with biblical concepts of health and healing.

Health, Healing and Shalom seeks to redress the compartmentalization and imbalance which plagues many in healthcare missions. Contributors to the book are Christian healthcare and development practitioners and theologians who share personal lessons and insights gained from years of grassroots-level service in inner cities of the USA and villages and cities around the world. It was their goal to practice according to a definition of health as being a state of complete physical, mental, social, and spiritual well-being, and not merely the absence of disease. Each chapter is well- referenced. Contributors' short bios and an index are included.

The Introductory section starts with a Foreword by Peter Yorgin, MD, in which he writes that this book reflects "best practices," and the thought and passion from the 2012 West Coast Healthcare Missions and Ministry Conference. Yorgin defines shalom and states that the purpose of this compendium is to provide some answers to questions initially grappled with by Daniel E. Fountain, MD, in a 1968 monograph:

1) What makes Christian medical missions "Christian"?

2) How do we prepare Christian healthcare missionaries so that they embrace a kingdom mindset?

3) What is health really supposed to mean to the church?

4) What should it look like for the church to be fully engaged in ministries of health, healing, and wholeness? (p. xiii-xvi) 
In the Introduction to the book, Bryant L. Myers, $\mathrm{PhD}$, gives an excellent overview of the contents, making it possible for the reader to prioritize the reading of chapters of special interest. He reviews global health status at the beginning of the $21^{\text {st }}$ century and reminds readers of historical contributions of Christians to healthcare, starting from the early centuries of the Christian Church and highlighting the more recent role in 1968 of the Christian Medical Commission (CMC) of the World Council of Churches, which "brought to light new models of communitybased primary health care at a time when the World Health Organization (WHO) was searching for alternative concepts for health care." The "conversation" between the CMC and WHO led to the Alma-Ata Declaration of 1978 that called for "Health for All by the Year 2000.” (p. xvii-xxxiii )

The commemorative chapter by Dr. Fountain is titled, "Putting the Whole Person Back Together - Lessons from Africa." $\mathrm{He}$ includes a number of faith-building accounts of the healing of bodily ailments that followed when patients experienced forgiveness for harmful emotions, old hurts, bitterness, rage, resentment, etc. Much credit is given by Fountain to a Zairian nurse counselor who was the "midwife" for many of the spiritual new births. Dr. Fountain's approach to whole person health care is fully explained in a training DVD, A Team Approach to Caring for the Whole Person, which is available from King University (globalhealth@king.edu).

Myers opens the first main section, "New Frontiers in Theology and Healthcare Missions" with two chapters. In the first of these, "Theological Reflections . . . ," he delves into the meanings and biblical usages of the Greek and Hebrew words for salvation and shalom. Since humans were created by God as relational beings and consist of mind, body, and soul, it is God's intention that they experience shalom, in other words, health, wholeness, and flourishing. The chapter develops these concepts with the aid of two diagrams, one showing the impact of $\sin$ on health and wholeness, and a second that indicates how the kingdom of God in Christ is meant to restore human relationships in all spheres of life. In the second chapter, (Chapter 3 in the book), "Announcing the Whole Gospel: Health, Healing and Christian Witness," Myers clearly states that "gospel" means "message," or "good news." He adds: "Messages are not messages unless they are announced." He urges medical professionals to explain their work as being empowered by God. Otherwise, people in "primal cultures" will ascribe healing to the spirits and gods of modern medicine. Myers suggests "a different way of thinking about proclamation" by referring to Lesslie Newbigin, missionary and missiologist, who made a case for evangelism in the early church as being the "second act not the first." (p. 41-55) In the third chapter of this first section, "Health Missions to Children in Crisis," David H. Scott, $\mathrm{PhD}$, delineates a framework for understanding "God's Heart for Children," which consists of seven affirmations from biblical texts and Christian doctrines.

The longest section of this volume is the middle portion: "New Frontiers in Healthcare Missions Practice." Here one can mine the wisdom of experienced Christian health and development workers who deal with a wide range of topics. This section contains chapters 5 through 12, summarized below.

Chapter 5 by Myers and Arnold Gorske, $\mathrm{MD}$, proposes that Community Based Health Screening and Education (CBHSE) be used by churches and their congregations to combat prevailing endemic diseases resulting from an unhealthy diet, inadequate exercise, and tobacco use. The teaching and learning style of CBHSE is participatory and problem-

Nov 2015. Christian Journal for Global Health 2(2): 78-81. 
solving. Training materials are available for free download from www.hepfdc.info.

In Chapter 6, drawing from their experience among the urban poor, Katy White, MD, MPH, and Kathleen Henry, PA-C, define kingdom health care as focused on Jesus Christ, holistic, and incarnational and focused on those with the least access to healthcare. In order to be effective, it must be rooted in Christian community. The authors describe common barriers to providing kingdom healthcare and motivate readers to practice in this way with two excellent examples from inner city Christian clinics in Chicago and Memphis, USA.

In this especially well-referenced Chapter 7, Ana Wong-McDonald, PhD, provides credibility for the data she presents about the impact of trauma on individuals and communities, both in the USA and around the world. She shows how restoration of shalom can only take place in community or at least in connection with one caring person.

In Chapter 8, W. Meredith Long, PhD, and Debbie Dortzbach, MN, MPH, relate the poignant story of Mary, an African woman, herself suffering with AIDS yet caring for her husband, his girlfriend and their child, all sick with AIDS and lying in one bed. The authors show how Jesus' love alone can heal broken relationships and enable those who "accompany" HIV/AIDS sufferers.

In Chapter 9, Michael J. Soderling, MD, estimates that 100,000 health professionals participate yearly in short-term medical missions at great cost of time, talent, and finance. He makes five proposals for changing old paradigms that rely on the dualistic worldview in which health professionals are trained. The most pertinent proposal for short-term missions is avoiding the harm that results from a collision of the holistic worldview of most people in "developing nations" with a secular definition of health and a focus on Western solutions for health problems. This chapter is a "must read" for short-term healthcare mission workers and administrators.

Chapter 10 by Rebecca Gagne Henderson, APRN, ACHPN, addresses shalom at the end of life by cooperating with "God's Magnificent Design" for the end of life. She gives an understandable explanation of the physiology of starvation and dehydration and offers practical ways to care for dying people without resorting to artificial nutrition and hydration, practices which can also have deleterious side effects.

Erin Dufault-Hunter, $\mathrm{PhD}$, reminds us in Chapter 11 that "Jesus wept" (John 11:35), so that we too may practice lament with patients who are suffering and in agony, even while we offer the Christian hope of God's ultimate triumph over disease and death.

The closing chapter in this section on "New Frontiers in Healthcare Missions Practice" is by two psychologists, Cynthia Eriksson, $\mathrm{PhD}$, and Ashley Wilkins, MA, together with Judith M. Tiersma Watson, PhD. These women offer tips to practitioners for maintaining healthy relationships with themselves, with ministry peers and within their organizations, in order to avoid burnout.

The third major section, "New Approaches in Healthcare Missions," begins with Chapter 13, "Overcoming Barriers in the City," by Anntippia Short, RN, MSN, CNE, and Isaac B. Voss, MPH. This chapter explores spiritual practices that can lead to transformed interpersonal relationships of shalom within the context of the city: hospitality, encounter, compassion, Christian witness, and justice. The authors define these terms with illustrations from their experience in the inner city of Los Angeles. This is a particularly helpful chapter for church volunteers as well as full-time practitioners

Nov 2015. Christian Journal for Global Health 2(2): 78-81. 
and can stand alone as a handout for orientation and training.

Chapters 14 and 15 are both about empowering lay health workers and local church volunteers to carry out healthcare in their communities. Although these models have mostly been used by missionaries in "developing countries" where much of the population does not have access to health care, in Chapter 14, Grace Tazelaar, MS, RN, and Carolyn Newhof, describe the impressive successes in lowering infant mortality through the work of Cary Christian Center's Home Visitors in Sharkey County, Mississippi. In Chapter 15, Terry Dalrymple, MDiv, and Jody Collinge, MD, describe Community Health Evangelism (CHE), a tool first developed by Stan Rowland in Uganda, but now used worldwide in varying cultural and religious contexts. The goal of CHE is the transformation of lives and communities through the power of the gospel by integrating Christian discipleship with disease prevention and community-based development. Training materials are available through the Global CHE Network. ${ }^{1}$
The concluding chapter, "Looking Forward in the Healthcare Missions Movement" is by Voss, Dufault-Hunter, and Rick Donlon, MD. The authors bring together the themes developed throughout the book and conclude that the healthcare missions movement needs to become committed to "kingdom healthcare that is identitytransforming, incarnational, integrative, and innovative."(265-282)

In conclusion, this book is highly recommended for all Christian healthcare workers so that they might be better able to treat the whole person in relation to his or her spiritual, mental, social, and physical environment, thus resulting in shalom physical and spiritual peace and well-being. It must be remembered that to accomplish this worthy goal will require a team approach and reliance on the Holy Spirit.

\section{References}

1. Global Community Health Evangelism Network. 2012a [CHE Lesson Plan Materials, CHE Training Info, and Training for Trainers]. Available at http://www.chenetwork.org/store.php

Competing Interests: None declared.

Correspondence: Cynthia B. Hale, cynthiabhale@gmail.com

Cite this article as: Hale, CB. Book review: Health, healing and shalom. Christian Journal for Global Health (May 2015), 2(2): 78-81.

(C) Hale, CB. This is an open-access article distributed under the terms of the Creative Commons Attribution License, which permits unrestricted use, distribution, and reproduction in any medium, provided the original author and source are properly cited. To view a copy of the license, visit http://creativecommons.org/licenses/by/3.0/

\section{wWw.cjgh.org}

Nov 2015. Christian Journal for Global Health 2(2): 78-81. 